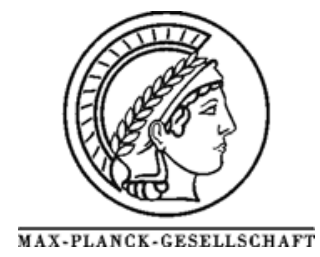

J.Catal. 230 (2005) 186-194

\title{
High-pressure X-ray photoelectron spectroscopy on palladium model hydrogenation catalysts Part1: Effect of gas ambient and temperature
}

\author{
D. Teschner ${ }^{1}{ }^{2 *}$, A. Pestryakov ${ }^{1}$, E. Kleimenov ${ }^{1}$, M. Hävecker ${ }^{1}$, H. Bluhm1, H. Sauer ${ }^{1}$, A. Knop-Gericke ${ }^{1}$, \\ R. Schlögl ${ }^{1}$
}

${ }^{1}$ Department of Inorganic Chemistry, Fritz-Haber-Institute of the MPG, Faradayweg 4-6, 14195 Berlin, Germany

${ }^{2}$ Institute of Isotope \& Surface Chemistry, CRC, Hungarian Academy of Sciences,

P. O. Box 77, Budapest, H-1525 Hungary.

${ }^{*}$ Corresponding author: e-mail teschner@fhi-berlin.mpg.de, phone +49 308413 5408, fax +49 3084134676

\begin{abstract}
In light of accumulating evidences highlighting the major role of operational conditions (gas composition, pressure, temperature) on the surface/bulk structure of catalytic materials, their characterization should involve more and more in-situ methods. We constructed a synchrotronbased high-pressure XPS (X-ray photoelectron spectroscopic) instrument, allowing us to investigate the surface and near-surface state of a catalyst in the mbar pressure range. We discuss here the surface characteristics of palladium samples as a function of gas-phase (hydrogen, oxygen) and temperature. We demonstrate that the surface region of catalytic materials behaves dynamically in its composition, always reflecting on its environment. For example, surface oxide can be formed on $\operatorname{Pd}(111)$ in oxygen which decomposes rapidly as the gas supply is switched off. The chemical nature of carbonaceous deposits depends also strongly on the operational conditions (gas-phase hydrogen, temperature). It is the first time that XPS investigation on palladium $\beta$-hydride was performed at RT. The possible drawbacks of using non-UHV setup e.g. fast carbon accumulation are also discussed.
\end{abstract}

Keywords: high-pressure XPS, palladium, hydrogen, carbonaceous deposits, surface oxide, palladium hydride

\section{Introduction}

Palladium is one of the most important hydrogenation catalysts, widely employed in industrial processes [17] but also in basic research [8-23]. Its practical importance in the interaction with various gases has stimulated widespreading investigations from the point of view of catalytic [8-12,14,15,17] and surface properties [13,16,18-23].

The field of hydrogen-metal interaction including chemisorption, relaxation, reconstruction and hydrogen dissolution is an extremely well studied area of surface science [20,21,24-33]. The energetics of hydrogen adsorption and dissolution in palladium (involvement of highly coordinated sites on the surface and in subsurface position) is well established, alas only for the case of "clean, surface science" conditions. In "dirty" real catalytic environments hardly any direct (spectroscopic) information is available, even though there is an enormous number of papers reporting on the major role of the partial pressure of hydrogen in various catalytic processes [12,34-37]. The role of hydrogen in these processes is still one of the important challenges in the mechanistic studies. The major drawback in investigating hydrogen-containing systems is the very low sensitivity of the spectroscopic methods toward hydrogen.

Carbonaceous deposits on metal surfaces represent a natural state of precious metal catalysts. Numerous species of carbon are observed on the surface of catalysts, ranging from carbides to hydrogen-rich aliphatic polymers. The chemical states of accumulated carbonaceous species on model palladium surfaces were often a matter of debate [38-42]. The majority of these studies were performed exsitu or in ultra-high vacuum (UHV), far away from the real catalytic conditions (this is often referred to as an example of the "pressure gap"). 
In the last decade, the development of in-situ characterization methods [43-49] helped to gain a better understanding of a working catalyst. In-situ studies provided evidence that the surface structure and the valence state of an active component can greatly be different in-situ as compared to UHV conditions, and weakly bonded adsorbed species or subsurface/bulk-solved components can be present at relevant catalytic conditions. The interaction of adsorbates with subsurface and bulk species can be essential for effective catalytic turnovers and the specific interplay between surface and subsurface/bulk species are mainly controlled by the operational conditions. Therefore in-situ techniques should play a crucial role in catalytic investigations. X-ray photoelectron spectroscopy (XPS) is one of the most widely used techniques; it is very powerful owing to its surface sensitivity. Conventionally, XPS is operated at UHV pressures, since the emitted photoelectrons are strongly scattered in a gas phase. However, the identification of the weakly adsorbed species and surface carbon present during the catalytic run is difficult in UHV-XPS, as the mere evacuation induces desorption or can change the chemical state of the surface species via loss of hydrogen [50-52]. To overcome these limitations high-pressure XPS chambers were designed already in the late 1970ies [50]. A number of high-pressure XPS experiments have been performed since [53-57]. Our in-situ XPS setup employs differentially pumped electrostatic lenses that allow to measure the sample in a gaseous environment (flowthrough mode) at pressures of up to 5 mbar.

We report here data collected using a $\operatorname{Pd}(111)$ single crystal and polycrystalline palladium foil. Part $I$ of this paper is meant to be an introductory article pinpointing possibilities and drawbacks of using high-pressure XPS with palladium and concentrating on the effects of experimental conditions (hydrogen pressure, oxygen, temperature) on the surface state of palladium samples. In the second part, as a step further, we present a real "in-situ" study to get a better understanding in the hydrogenation processes, using trans-2-pentene as a model reactant.

\section{Experimental}

The in-situ XPS experiments were performed at beam lines U49/2-PGM1 and UE56/2-PGM2 at BESSY in Berlin. Our set-up operates analogously as the instrument described in Ref. [58]. A differentially pumped electrostatic lens system is the key feature of our set-up, allowing us to investigate the sample in the mbar pressure region. The sample position is controlled by a 3D manipulator and the sample is placed $\sim 20 \mathrm{~mm}$ away from the X-ray window and $\sim 2 \mathrm{~mm}$ in front of the first aperture, which is the entrance to the electrostatic lens system. The surface normal of the sample is parallel to the optical axis of our lens system while incidence $\mathrm{x}$-rays irradiate the sample under $55^{\circ}$ from the surface normal. C $1 \mathrm{~s}$ and $\mathrm{Pd} 3 \mathrm{~d}$ spectra were recorded with photon energies of $\mathrm{h} v=660$ and $720 \mathrm{eV}$ (electron kinetic energy $\sim 370 \mathrm{eV}$ ), respectively (if not otherwise stated). Valence band spectra were obtained using $150 \mathrm{eV}$ photon excitation. The overall spectral resolution measured by argon ( $\mathrm{Ar} 2 \mathrm{p}$ ) was about $0.2 \mathrm{eV}$ at both beamlines. The binding energies were calibrated against the Fermi level of the samples. Decomposition of the $\mathrm{C} 1 \mathrm{~s}$ region was performed using Gauss convoluted DoniachSunjic curves (DS*) [59]. The Pd 3d peaks were fitted using Gauss-Lorentz profiles with exponential tail. This latter gave a much better agreement with the experimental data (better Chi-square values) than the often-used DS* function. The atomic composition was calculated using energy dependent photoionization cross sections [60] assuming a homogeneous distribution of the various elements in the information depth. The inelastic mean free path for the used electron energy is approx. $9 \AA$ for palladium and $13 \AA$ for carbon [61]. No impurity other than carbon was observed, thus $\%(\mathrm{C} 1 \mathrm{~s})+\%(\mathrm{Pd} 3 \mathrm{~d})=100 \% . \operatorname{Pd}(111)$ single crystal and polycrystalline palladium foil (Goodfellow, purity $99.99 \%$ ) were investigated in this study. The samples were mounted on a temperature-controlled heater and were cleaned from hydrocarbon contamination by first heating them in oxygen $\left(10^{-4} \mathrm{mbar}, 973 \mathrm{~K}\right)$ and then flushing to $1073 \mathrm{~K}$ in vacuum. Due to the residual gas pressure of $10^{-7} \mathrm{mbar}$ in our chamber, the sample was always covered by some hydrocarbon contamination. Gas flow into the reaction cell was controlled using calibrated mass flow controllers and leak valves. The pressure in the experimental cell was varied from high vacuum $\left(10^{-7} \mathrm{mbar}\right)$ up to $4 \mathrm{mbar}$, and the sample was investigated at temperatures from $298 \ldots 623 \mathrm{~K}$. The experimental cell is connected to a transfer chamber where treatments can be carried out in the $10^{-6}$ mbar to 1 bar pressure range. For the preparation of palladium $\beta$-hydride the following procedure was used. First, a piece of Pd foil was cleaned from carbon contamination by sputtering and by oxygen treatment ( $473 \mathrm{~K}, 0.15$ mbar) and then the surface oxide was decomposed by evacuation. Hydrogen (1 bar) was introduced and the sample was hold at $338 \mathrm{~K}$ for 20 min, then cooled down to RT. After one hour atmospheric hydrogen treatment, the pressure was slowly decreased to 2.3 mbar and under this controlled ambient the sample was transferred back to the experimental chamber where the same hydrogen pressure was set previously.

\section{Results}

Before we go into the detailed analysis of the spectra, we would like to draw the attention to a phenomenon, which is not present in conventional XPS measurements. When Pd was measured in hydrogen, additional peaks appeared in the spectra; the relative intensity of the new peaks showing a positive correlation with the introduced hydrogen pressure. Fig. 1, 2 show the $\mathrm{Pd} 3 \mathrm{~d}$ and the $\mathrm{C}$ 1s region in the presence of 3 mbar hydrogen at room temperature. In addition to the expected peaks, additional peaks at higher $\mathrm{BE}$ (i.e. lower KE) are present in the spectra. The energy separation of the original and the additional peaks is constant $(\sim 12.7-12.8 \mathrm{eV})$, and the new peaks are strongly 
broadened at the high-energy side. The correlation of the peak intensity with the $\mathrm{H}_{2}$ pressure and the energy separation indicates that the new peaks are due to the inelastic scattering of the photoelectrons on the hydrogen molecules. During this process the hydrogen $1 \mathrm{~s}$ electrons are excited mainly to the $2 \mathrm{p}$ state $(\mathrm{E}=12.6 \mathrm{eV})$, but also to higher Rydberg transitions, as well as to the vacuum continuum ()E $>15.4 \mathrm{eV})$.

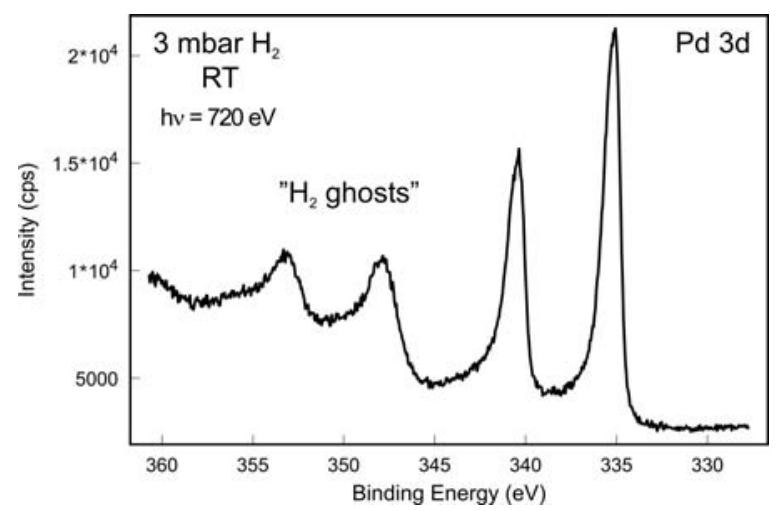

Figure 1: $\mathrm{Pd} 3 \mathrm{~d}$ region of palladium foil in the presence of 3 mbar hydrogen.

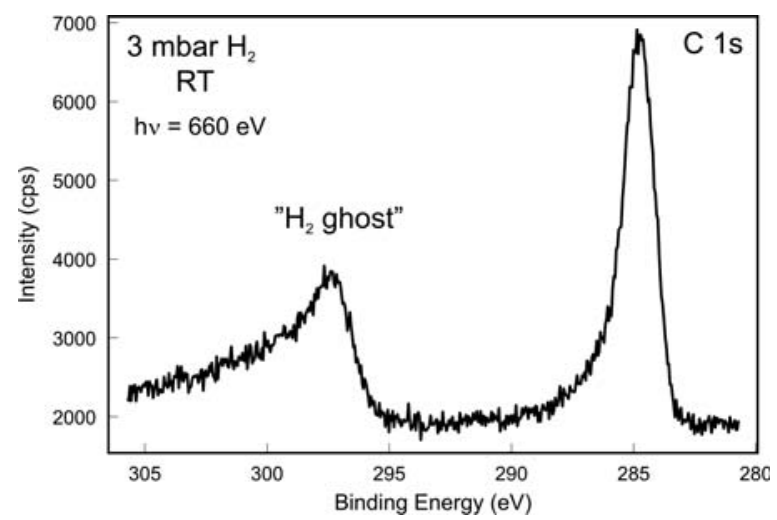

Figure 2: $\mathrm{C}$ 1s region of palladium foil in the presence of 3 mbar hydrogen.

When palladium foil is measured without any treatment in vacuum, the carbon content within the probing depth in our experiments is larger than $95 \%$. After a cleaning cycle (see Experimental) the $\mathrm{C}$ content decreased to $30 \%$, which is still a high value. Part of this residual carbon was most probably present also during the cleaning procedure (not removed) in grain boundaries, but part of it might originate from the re-adsorption from the residual contaminants in the chamber atmosphere during the cooling period. The base pressure in our experimental cell is $\sim 10^{-7} \mathrm{mbar}$ (although mainly water), which makes it difficult to prepare and maintain clean (carbon free) metal surfaces in nonoxidizing environments. Consequently, we observe carbon accumulation over time at our base pressure of $10^{-7} \mathrm{mbar}$ (Fig. 3 curves 1 and 2), without directly introducing any hydrocarbons on purpose. In a separate experiment, however, using oxidizing conditions $\left(0.06 \mathrm{mbar}_{2}\right.$ at $\left.300{ }^{\circ} \mathrm{C}\right)$ we were able to prepare a clean $\operatorname{Pd}$ surface on a $\operatorname{Pd}(111)$ single crystal (Fig. 5). In oxygen (0.06 mbar $\left.\mathrm{O}_{2}, 573 \mathrm{~K}\right)$, the $\mathrm{Pd} 3 \mathrm{~d}$ peak contains contribution from bulk $\mathrm{Pd}(\mathrm{BE}=$
$335.0 \mathrm{eV}$ ) and two additional components at BE's of 335.6 and $336.3 \mathrm{eV}$ (energy separation of +0.6 and $+1.3 \mathrm{eV}$ ), while the $\mathrm{C} 1 \mathrm{~s}$ region does not show any carbon being present (not shown). The Pd3d peak with BE of $335.6 \mathrm{eV}$ might be due to adsorbed oxygen while the $336.3 \mathrm{eV}$ peak could be due to $\mathrm{PdO}[62,63]$. However, recently [64] a new surface oxide phase $\mathrm{Pd}_{5} \mathrm{O}_{4}$ was identified on $\mathrm{Pd}(111)$ with exactly the same BE spacing as observed here, and thus we identify the high $\mathrm{BE}$ peaks as due to $\mathrm{Pd}_{5} \mathrm{O}_{4}$. The surface oxide phase in Ref. [58] was prepared at $573 \mathrm{~K}$ by exposing the $\operatorname{Pd}(111)$ surface to $3000 \mathrm{~L}$ of oxygen $\left(5^{*} 10^{-6} \mathrm{mbar}\right.$ for $600 \mathrm{~s})$, but after that the temperature was quenched to RT, at which the Pd3d spectrum was recorded. When the oxygen flow is switched off in our experiment (still at $573 \mathrm{~K}$ ), the oxide phase is quickly removed ( $\sim 15 \%$ of the oxide might be still there, calculated from the decrease of the $335.6 \mathrm{eV}$ peak area) and the spectrum resembles the well-known pattern with the surface core level shift of about $-0.3 \mathrm{eV}$. 15 min after switching off the oxygen the surface already contains a few percent of carbon. When the temperature is decreased the accumulation of $\mathrm{C}$ on the surface increased further.

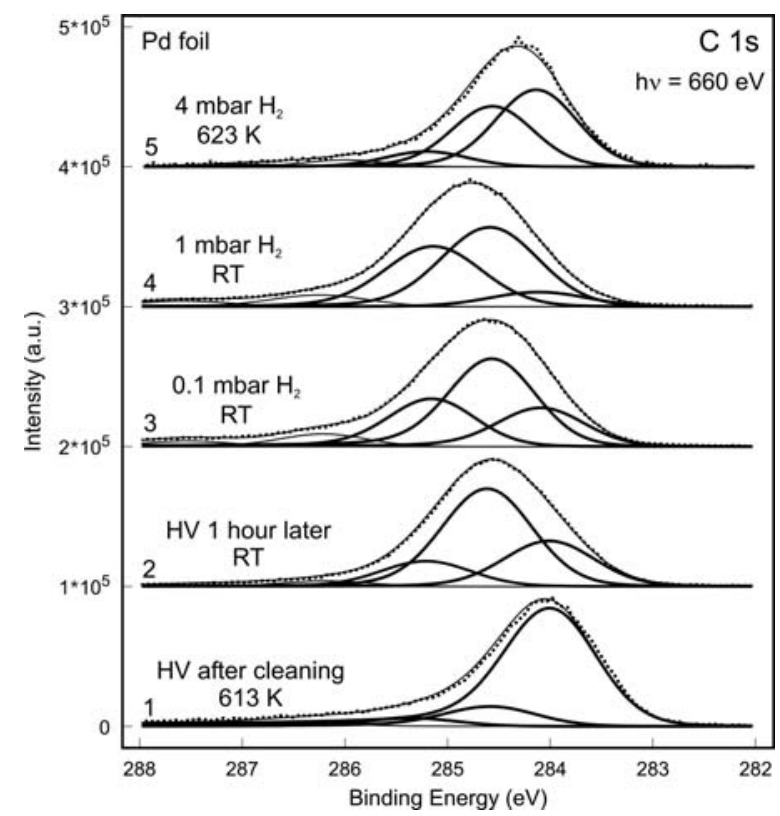

Figure 3: $\mathrm{C} 1 \mathrm{~s}$ region of palladium foil at different experimental conditions. Incident photon energy, hv $=660 \mathrm{eV}$. Dashed line: measured data, full line: fits.

One-hour stay of Pd foil in HV and decreasing the temperature from $613 \mathrm{~K}$ to room temperature doubled the amount of carbon, while the position of the maximum is shifted by $+0.5 \mathrm{eV}$ to $284.55 \mathrm{eV}$ and the peak got broader (Fig. 3). The carbon accumulation was slightly enhanced by the high flux of the synchrotron beam. Introduction of hydrogen shifted the $\mathrm{C} 1 \mathrm{~s}$ peak further towards higher BE and the amount of carbon increased as well. Increasing the temperature $\left(350^{\circ} \mathrm{C}\right)$ in hydrogen ambient shifted the peak back towards lower binding energies. Even higher hydrogen pressure (4 mbar) was not able to compensate this effect. The carbon content in 4 mbar $\mathrm{H}_{2}$ at $623 \mathrm{~K}$ decreased to $70 \%(-10 \%)$. The total amount of carbon measured on 


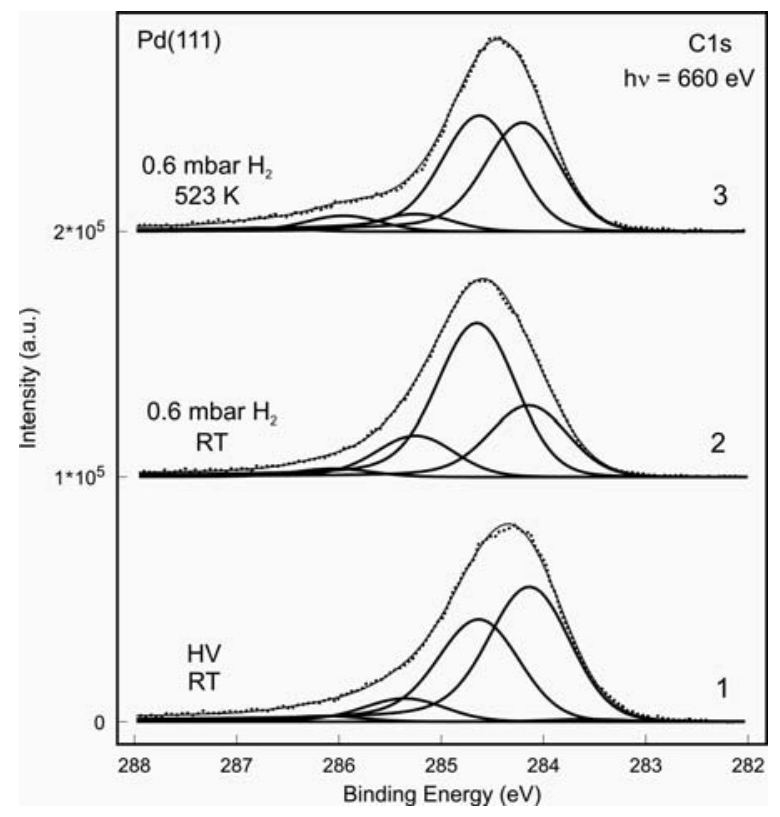

Figure 4: $\mathrm{C}$ 1s region $\operatorname{Pd}(111)$ single crystal at different experimental conditions. Incident photon energy, $h v=660$ eV. Dashed line: measured data, full line: fits.

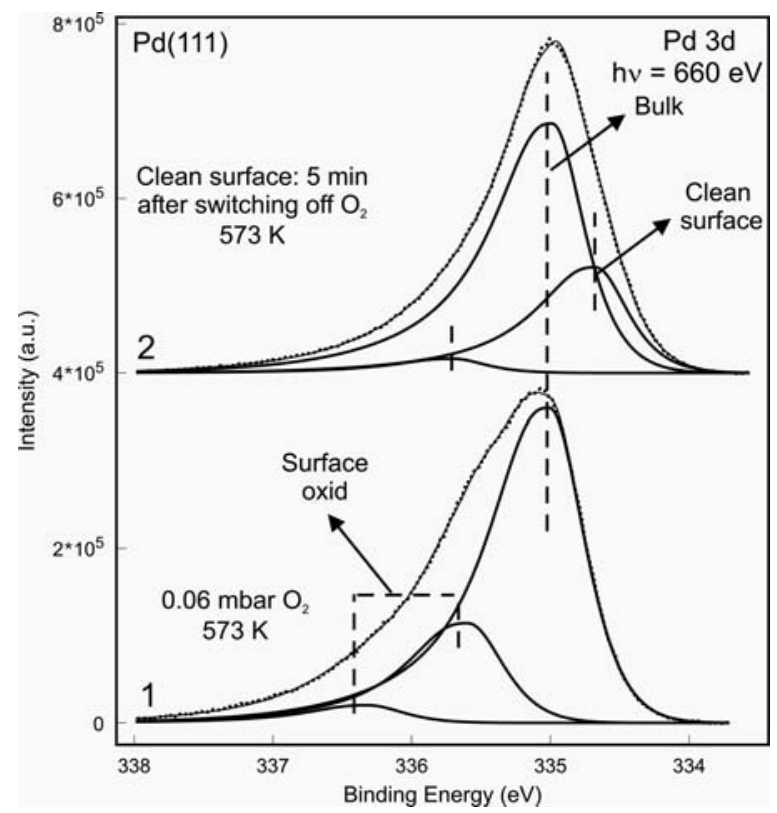

Figure 5: $\mathrm{Pd} 3 \mathrm{~d}(5 / 2)$ region of $\mathrm{Pd}(111)$ single crystal in the presence of $0.06 \mathrm{mbar}_{2}$ at $573 \mathrm{~K}$ (1) and right after switching off $\mathrm{O}_{2}$ (2). Incident photon energy, $\mathrm{h} v=660 \mathrm{eV}$. Dashed line: measured data, full line: fits.

$\operatorname{Pd}(111)$ was generally less than on the foil (30-40\% vs. 70 $80 \%$ ). The trends in the $\mathrm{C}$ content observed as a function of hydrogen pressure and temperature, however, were similar for foil and single crystal (Fig. 4). The measured spectra were analyzed by a least square fitting procedure. For this analysis we used not just one main carbon component for several reasons. Since the absolute binding energy scale can be calibrated quite accurately $( \pm 0.01 \mathrm{eV})$, one reason was that binding energy shifts of up to $0.75 \mathrm{eV}$ could be observed. Second, although the C1s peaks were not well resolved, however the shape of them was markedly differ- ent. Third, the full-with-at-half-maximum (FWHM) varied also (up to $\sim 25 \%$ ). And last but not least, depth-profiling experiments (see Part II) revealed also the presence of different carbon species, as the shape of the C1s peak changed with the photon energy, obtaining thus spectra with different information depth. To be able to satisfactorily fit the main $\mathrm{C} 1 \mathrm{~s}$ region $(283-286 \mathrm{eV})$ we need at least 3 components for the analysis. The binding energies for these three main components were found to be at $284.1 \pm 0.05,284.55 \pm 0.05$ and $285.2 \pm 0.05 \mathrm{eV}$. The exact identification of these species is not unambiguous, however, according to the literature [65-68] they correspond to (chain) carbon attached likely by several bonds to the metal, to graphitic carbon, and to aliphatic carbon containing hydrogen, respectively. Since the chemical shift of the different species reflects their chemical environment, and since in our system we have three main elements $(\mathrm{Pd}, \mathrm{C}, \mathrm{H})$ we will use the following nomenclature for these three main carbon components (Table 1): carbon connected to palladium $(C-P d ; \mathrm{BE}=284.1 \mathrm{eV})$, carbon connected to carbon $(C-C ; \mathrm{BE}=284.55 \mathrm{eV})$, and carbon connected to hydrogen $(C-H ; \mathrm{BE}=285.2 \mathrm{eV})$. The small peaks found above $286 \mathrm{eV}$ correspond to some oxygen containing carbon.

Table 1: The main carbon types, their signs used in the text and their binding energy positions

\begin{tabular}{ccc}
\hline C type & Sign & BE $[\mathrm{eV}]$ \\
\hline $\begin{array}{c}\text { carbon connected } \\
\text { to palladium } \\
\text { carbon connected } \\
\text { to carbon }\end{array}$ & $\mathrm{C}-\mathrm{Pd}$ & $284.1 \pm 0.05$ \\
$\begin{array}{c}\text { carbon connected } \\
\text { to hydrogen }\end{array}$ & $\mathrm{C}-\mathrm{C}$ & $284.55 \pm 0.05$ \\
\hline
\end{tabular}

Initially, after a cleaning procedure and above $573 \mathrm{~K}$ mainly $C-P d$ is present (Fig. 3 curve 1). This carbon is most probably one or two-dimensional - atomically dispersed or in islands - and has obviously very low hydrogen content. According to theoretical calculations [69], the binding energy of atomically dispersed carbon with surface or subsurface location is in the range of $284-284.5 \mathrm{eV}$. Thus one part of this C-Pd species may represent subsurface carbon. During the carbon accumulation from the background the initial "layer" starts to reconstruct and when the amount of carbon is high enough, threedimensional structures form (high contribution of graphitic carbon, Fig. 3 curve 2). When the surface is then exposed to hydrogen mainly the $C-P d$ type carbon is transferred to $\mathrm{C}-\mathrm{H}$ type (Fig. 3 curves 3 and 4), while heating induces loss of hydrogen (Fig. 3 curve 5, Fig. 4 curve 3). Interestingly, the presence of 4 mbar hydrogen seems to be negligible compared to the effect of heating, since the $\mathrm{C}-\mathrm{H}$ component at this stage was very low. High temperature favors the formation of $C-P d$ type carbon. Carbon on palladium single crystal shows the same general behavior as observed for the foil, however, its ability to transform $C-P d$ to $C-H$ is much smaller. 


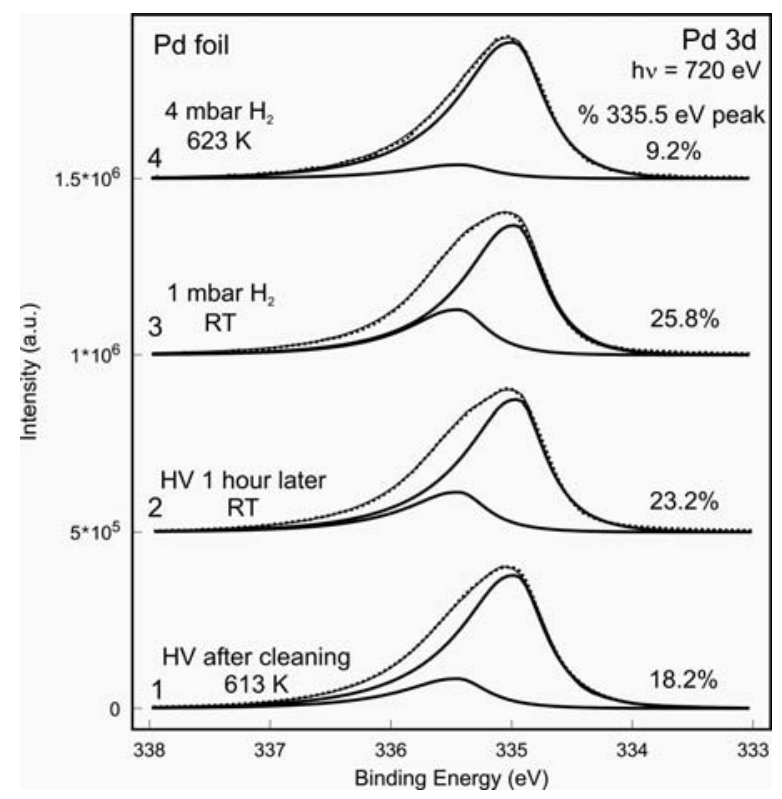

Figure 6: $\mathrm{Pd} 3 \mathrm{~d}(5 / 2)$ region of palladium foil at different experimental conditions. Incident photon energy, $h v=720$ eV. Dashed line: measured data, full line: fits. The relative intensity of the $335.5 \mathrm{eV}$ component is also included.

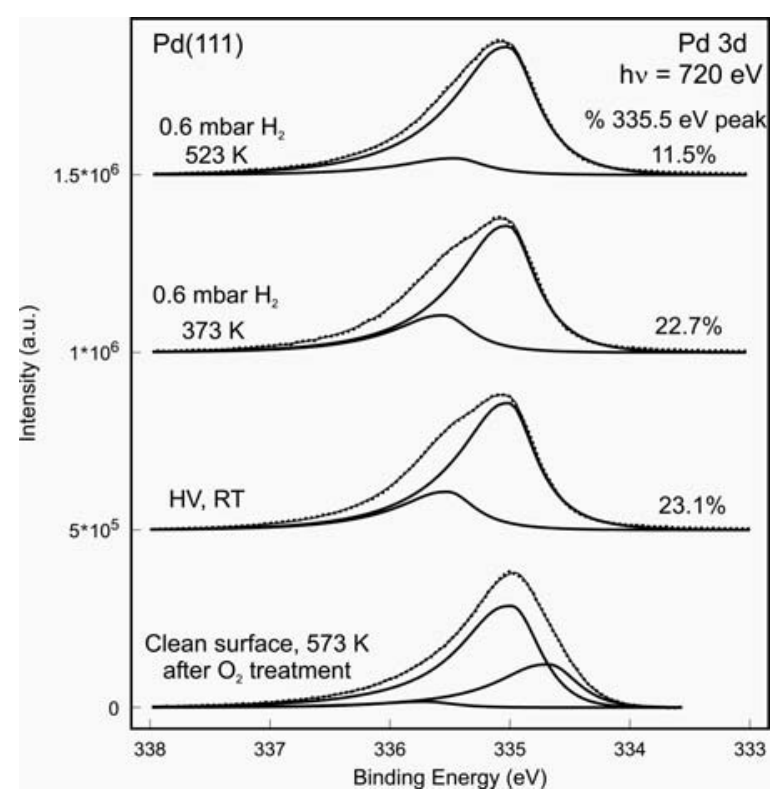

Figure 7: $\mathrm{Pd} 3 \mathrm{~d}(5 / 2)$ region of $\mathrm{Pd}(111)$ single crystal at different experimental conditions. Incident photon energy, $\mathrm{h} v=720 \mathrm{eV}$ (except that after $\mathrm{O}_{2}$ treatment, $660 \mathrm{eV}$ ). Dashed line: measured data, full line: fits. The relative intensity of the $335.5 \mathrm{eV}$ component is also included.

Figure 6, 7 show the complementary Pd $3 \mathrm{~d}$ data to the $\mathrm{C} 1 \mathrm{~s}$ spectra discussed above. The spectrum of the clean surface from Fig. 5 is also included in Fig. 7 for better comparison. In the literature $[19,70]$ mainly three types of metallic palladium species are discussed, namely clean surface palladium atoms (surface core level shift) with a BE of $3 \mathrm{~d}_{5 / 2} \sim 334.7 \mathrm{eV}$, bulk palladium at $\sim 335.0 \mathrm{eV}$ and surface palladium atoms covered by (or bonded to) differ- ent types of adsorbed species. Binding energies for the last type were found in the range of 335.3-335.6 eV. Since our palladium is always covered by some type of carbon (in non-oxidizing conditions), it is not surprising that our $\mathrm{Pd} 3 \mathrm{~d}$ least square fits did not show any component at $\sim 334.7 \mathrm{eV}$ (SCLS). Thus the Pd $3 \mathrm{~d}$ core level peaks were fitted only by two components; bulk Pd and adsorbate-induced Pd. After cleaning in high vacuum, the adsorbate-induced surface peak was already present. Its intensity increases during the carbon accumulation period. Its highest intensity was reached in hydrogen ambient (Fig. 6 curve 3), when the total amount of carbon was highest as well. Interestingly, temperature treatment $(623 \mathrm{~K})$ removed most of this component; the lowest level $(9.2 \%)$ of this component was reached under those conditions, even though the total carbon content was still 70\%. Here again, $\operatorname{Pd}(111)$ behaves quite similar to the $\mathrm{Pd}$ foil. It is interesting to mention, however that, although the relative amount of the adsorbate-induced surface Pd peak is rather comparable for the two samples at the steady $\mathrm{HV}$ and at high $\mathrm{T}$ conditions ( $\mathrm{Pd}$ foil: $23.2 \%$ and $9.2 \%$ and $\operatorname{Pd}(111): 23.1 \%$ and $11.5 \%$ ), the total amount of carbon is roughly twice as high for the $\mathrm{Pd}$ foil. In light of the above data, the total amount of carbon cannot be correlated to the adsorbate-induced surface Pd component.

Since we have seen that it was impossible to correlate the adsorbate-induced surface Pd peak to the total amount of carbon, we have plotted the main carbon components as a function of the relative abundance of $\mathrm{Pd} 3 \mathrm{~d}$ $335.5 \mathrm{eV}$ peak (Fig. 8). It is difficult to draw unambiguous conclusions, however some remarkable observations can be done. First, some loose correlation can be suspected from most of the data points as indicated by the full lines. According to these, the graphitic phase appears to be almost independent of and the other two carbon species seems to have a sort of complementary positive and negative correlation to the $335.5 \mathrm{eV}$ palladium component. Surprisingly, the $C-P d$ species has a negative while the $C-H$ component a positive correlation to the adsorbate-induced surface Pd peak. Second, the first data point after the cleaning procedure in HV (indicated by circled symbols) does absolutely not fit into the trendlines, demonstrating that UHV and insitu (with gas phase) conditions might differ quite strongly from each other (pressure gap).

\section{Discussion}

In the previous section we presented XP spectra in varying gas phase environment at different temperatures that demonstrated the dynamic behavior of the surface in the palladium system. These changes were only detectable in-situ; no "postmortem" examination enables to reveal the alterations. This was demonstrated unequivocally in Fig. 5 when the two successive scans on Pd3d showed different spectra; the surface oxide could only be observed in $\mathrm{O}_{2}$ ambient and decomposed rapidly in HV, leaving behind pure metallic palladium. Due to the background pressure of 


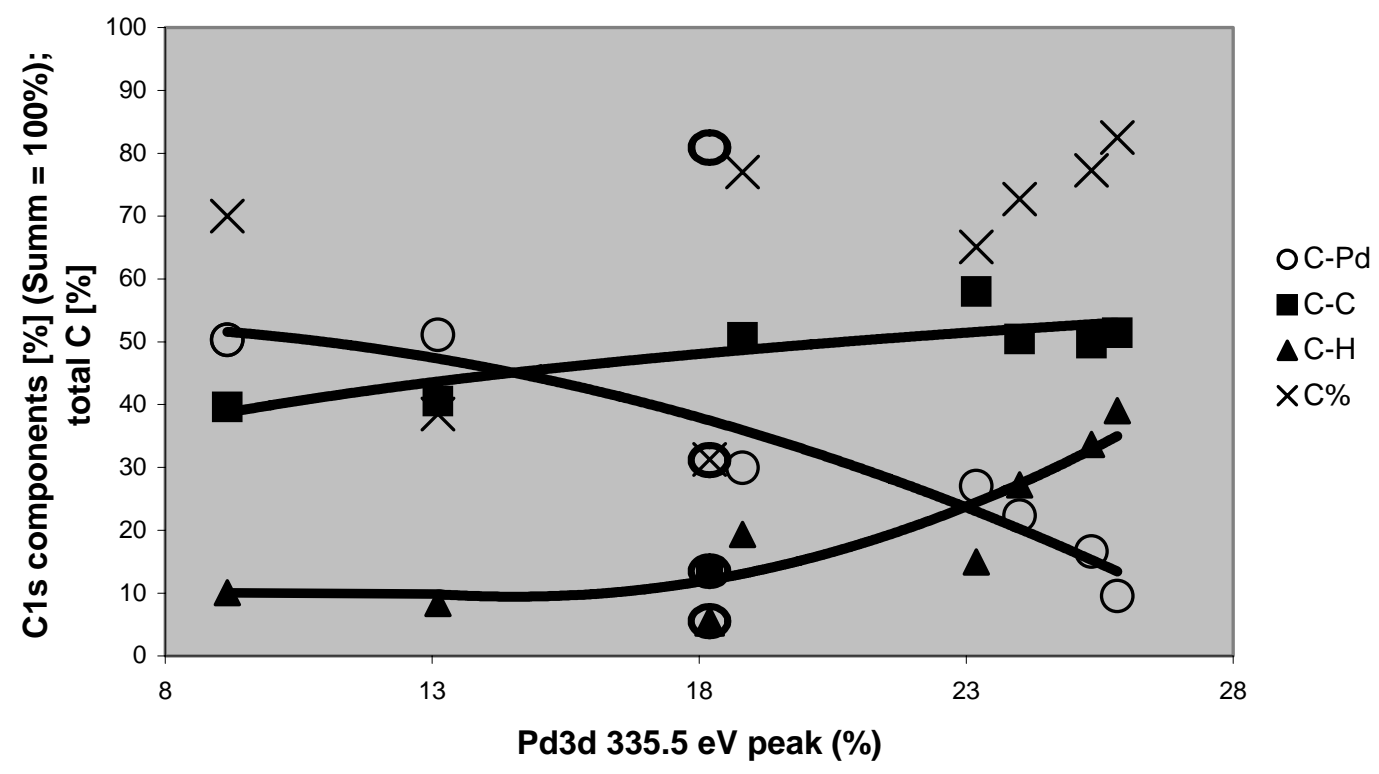

Figure 8: Correlation of the total carbon content and the relative amounts of the individual carbon types as a function of the relative amount of adsorbed-induced Pd 3d component. Pd foil data are included. Most of the data points originate from Fig. 2 and 4.

$10^{-7}$ mbar, however, the surface gets quickly contaminated by carbonaceous species. An additional source of carbon accumulation is a beam-enhanced deposition of carbon containing molecules from the gas-phase background. The possibility of such quick surface contamination is therefore the "price to pay" when using non-UHV XPS chambers. In our mind, however, this is the only way to perform XPS measurements mimicking realistic catalytic conditions.

We identified three main types of surface carbon in our system: carbon in interaction with palladium, carbon connected to carbon, and "hydrogenated" carbon. The hydrogen content of the carbonaceous deposit depends on the hydrogen pressure and the temperature; higher $\mathrm{p}\left(\mathrm{H}_{2}\right)$ and lower temperature favor the formation of $\mathrm{C}-\mathrm{H}$ species. At elevated temperature the hydrogen content is low and the $C$-Pd component is increased. The spectrum measured in 4 mbar $\mathrm{H}_{2}$ at $623 \mathrm{~K}$ indicates that the rate of $\mathrm{C}-\mathrm{H}$ bond cleavage is much faster than its generation and hydrogen readily desorbs (not surprisingly) at this $\mathrm{T}$.

We have seen that at higher temperature (mainly $C-C$ and $C-P d$ is present) the adsorbate-induced surface $\mathrm{Pd}$ component (BE: $335.5 \mathrm{eV}$ ) is small $(9-11 \%)$, although the total carbon content is still very high (up to $70 \%$ ). This apparent contradiction can be explained assuming that part of the carbon is located not directly on the palladium surface but in 3-D graphitic islands and part of the carbon is atomically dispersed in the subsurface region. The higher $C-P d$ component on the foil points to more corrugated palladium surface with carbon in in/sub-surface position. The loose negative correlation between the surface-related adsorbate-induced Pd component $(\mathrm{Pd} 3 \mathrm{~d})$ and the $C-P d(\mathrm{C} 1 \mathrm{~s})$ strengthens the localization of $C-P d$ not to the surface but to the subsurface region. The defect-rich polycrystalline surface ensures efficient carbon infiltration, which leads to expansion of the palladium lattice (see paragraph about
HRTEM in Part II). Considering the presence of subsurface carbon, the $C-P d$ to $C-H$ transformation can be explained by the direct hydrogenation of atomically dispersed carbon and by a more complex process, hydrogen entering the subsurface position replacing carbon, which will then either pushed deeper into the bulk or up to the surface, where its hydrogenation can take place.

The $\operatorname{Pd}(111)$ single crystal hydrogenates its carbon deposit much weaker than the polycrystalline foil, although the carbon content on the foil was approximately twice as high. Assuming that the rate of hydrogen dissociation is much faster on palladium (even in its highly covered state) as on the carbonaceous deposits, the polycrystalline sample promotes the (re)hydrogenation of the (sub)surface carbon much stronger than $\operatorname{Pd}(111)$. The palladium foil interacts with the carbon more "intimately", which can be deduced from the higher abundance of $C-P d$ species on the foil and from the above mentioned higher re-hydrogenation ability.

Hydrogen interacts with palladium readily giving rise to ad- and absorbed phases. The equilibrium diagram of the palladium-hydrogen system with the two homogenous hydride phases ( $\alpha$ and $\beta$ ) and the heterogeneous two-phase below the critical temperature is well known [29,71,72]. However, in "surface-science" conditions, as demonstrated by ongoing debates about different hydrogen species, the observed patterns (TDS, LEED, HREEL etc.) strongly depend on the sample- and adsorption temperature, on the introduced amount of hydrogen, on the surface cleanness and partly also on the exposed surface. Under our experimental condition with $\mathrm{pH}_{2}$ in the mbar range palladium is expected to be in the $\alpha$ phase, the equilibrium pressure for phase transition towards the $\beta$ phase at RT being at about 7 10 mbar. No XPS data exists in the literature in realistic conditions for the two hydride phases. The available measurements [73-75] were done after generating the $\beta$ phase 
$\left(\mathrm{PdH}_{\sim 0.6}\right)$ at RT and subsequently cooling to $\sim 100 \mathrm{~K}$, at which temperature the equilibrium pressure is in UHV condition. The results indicated that the d-band is modified and shifted relative to $\mathrm{E}_{\mathrm{F}}$, that the density of states at $\mathrm{E}_{\mathrm{F}}$ decreases, a new hydrogen induced band is formed about 7 $8 \mathrm{eV}$ below $\mathrm{E}_{\mathrm{F}}$, and the $\mathrm{Pd} 3 \mathrm{~d}$ core level shifts by $\sim+0.2 \mathrm{eV}$ to higher $\mathrm{BE}$ and becomes more symmetric. According to these papers all those findings should correspond to the $\beta$ phase, while no information is obtained on the $\alpha$ phase. Our results resemble none of the literature findings. (For a discussion of the valence band spectra see Part II.) Therefore, if the literature data are transferable to catalytically realistic temperatures, our measurements were done in the $\alpha$ phase regime and the $\alpha$ phase does not exhibit the above spectroscopic pattern. Additionally, we have carried out experiments to generate and measure the $\beta$ hydride phase, as well.

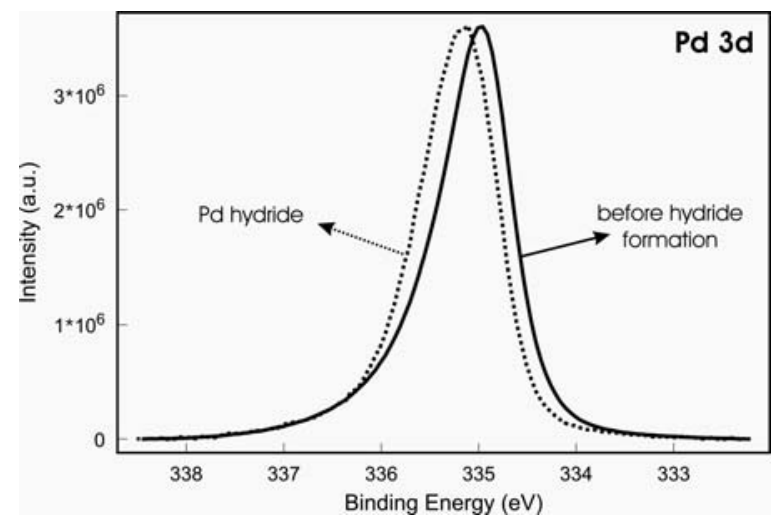

Figure 9: $\mathrm{Pd} 3 \mathrm{~d}(5 / 2)$ of $\mathrm{Pd}$ foil before hydride formation and as a $\beta$ hydride.

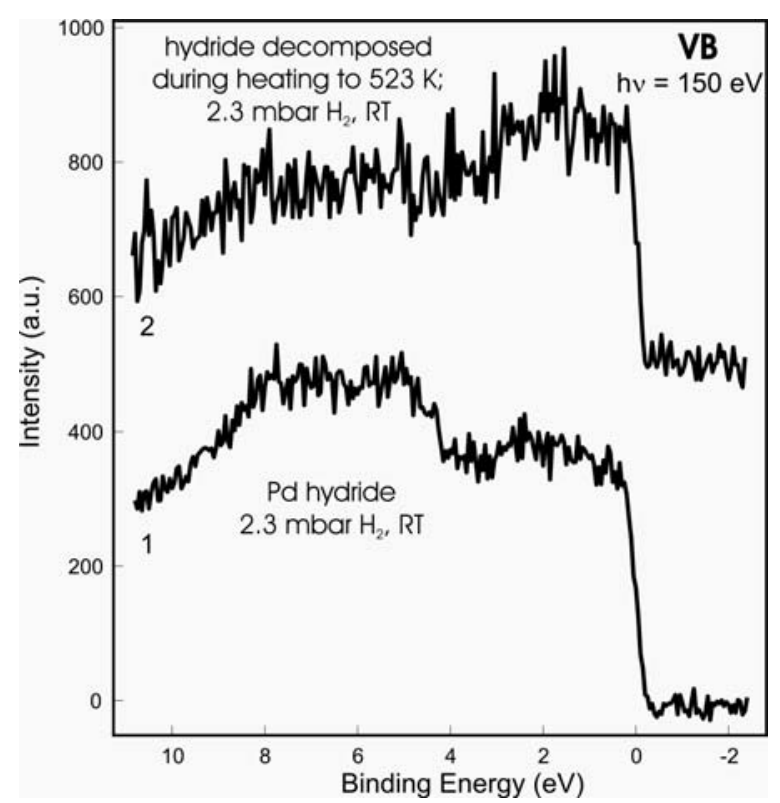

Figure 10: Valence band of Pd foil in the $\beta$ hydride state (1) and after hydride decomposition (2). RT and $\sim 2.3$ mbar $\mathrm{H}_{2}$.
It is well known $[29,71]$ that the $\alpha / \beta$ transformation exhibits a characteristic hysteresis. The decomposition of the $\beta$ phase takes place at lower equilibrium hydrogen pressure than its generation. Therefore once producing this phase there might be a chance to measure it at pressures that were not enough to the generation. The preparation we used is explained in the Experimental section. Figure 9 and 10 show the Pd $3 \mathrm{~d}$ and valence band region of the palladium foil respectively, after the atmospheric hydrogen treatment but in 2.3 mbar hydrogen. The $3 \mathrm{~d}$ core level displays after generating the $\beta$ phase a $0.18 \mathrm{eV}$ binding energy shift and the asymmetry of the peak decreased as was shown at low $\mathrm{T}$ and predicted by the theory [73,74,31]. Although the quality of the VB spectra is very poor, the similarity to the low temperature data concerning the hydrogen-induced band is obvious. This band was absent after heating the sample to $523 \mathrm{~K}$. Therefore the presence of these features is characteristic for the $\beta$ hydride, also at room temperature.

\section{Conclusion}

High-pressure XPS is an excellent tool for studying the electronic structure of catalysts under gas ambient in the mbar pressure range. We demonstrated that the surface is dynamic and reflects always on its ambient (gas phase, pressure, temperature). Surface oxide was observed on $\operatorname{Pd}(111)$ at $573 \mathrm{~K}$, which decomposed as the oxygen supply was switched off. Owing to the high surface sensitivity of XPS, impurity accumulation by using non-UHV conditions (non-UHV chamber, non-infinite gas purity) is blown up. Carbon accumulated on palladium from the gas basepressure of the chamber. The carbonaceous layer on the surface was, however, strongly influenced by the presence of hydrogen and by the temperature. Few (1-4) mbar of hydrogen was not enough to form palladium $\beta$ hydride. On the other hand, making use of the hysteresis of the $\alpha / \beta$ transformation, the $\beta$ phase can be stabilized in this pressure range. Its spectroscopic characteristics seem to be similar to literature data recorded at $\sim 100 \mathrm{~K}$.

\section{Acknowledgements}

Financial support from ATHENA Project is gratefully acknowledged. One of us thanks also for the RomanHerzog-Stipendium by the Humboldt Foundation. In addition, we thank the BESSY staff for their continual support during the XPS measurements. 


\section{References}

[1] R. A. Dalla Betta, K. Tsurumi, Shoji, US Patent 5258349 (1993).

[2] S. Morikawa, S. Samejima, M. Yoshitake, N. Tatematsu, Jpn Patent 3-099026 (1991).

[3] J. Moore, J. O’Kell, EU Patent 508660 (1992).

[4] A. Chauvel, G. Lefebvre, Petrochemical Processes 2 (1989) 36.

[5] Hoechst, EP. 330853 (1989), EP. 403950 (1990), EP. 431478 (1991), EP. 519435 (1992).

[6] R. B. Anderson, K. C. Stein, J. J. Feenan, L. E. J. Hofer, Ind. Eng. Chem. 53 (1961) 809.

[7] W. K. Lam, L. Lloyd, Oil Gas 27 (1972) 66

[8] G. C. Bond, P. B. Wells, Adv. Catal. 15 (1964) 91.

[9] T. Mallat, A. Baiker, Catal. Today 19 (1994) 247.

[10] M. L. Derrien, Stud. Surf. Sci. Catal. 27 (1986) 613.

[11] D. Stacchiola, S. Azad, L. Burkholder, W. T. Tysoe, J. Phys. Chem. B 105 (2001) 11233.

[12] B. Heinrichs, J.-P. Schoebrechts, J.-P. Pirard, J. Catal. 200 (2001) 309.

[13] G. B. Hoflund, H. A. E. Hagelin, J. F. Weaver, G. N. Salaita, Appl. Surf. Sci. 205 (2003) 102.

[14] C. F. Cullis, B. M. Willatt, J. Catal. 83 (1982) 267.

[15] J. H. Kang, E. W. Shin, W. J. Kim, J. D. Park, S. H. Moon, J. Catal. 208 (2002) 310.

[16] W.-J. Shen, Y. Ichihashi, H. Ando, Y. Matsumara, M. Okumura, M. Haruta, Appl. Catal. A 217 (2001) 231.

[17] A. Trovarelli, Catal. Rev.-Sci. Eng. 38 (1996) 439.

[18] G. Tourillon, A. Cassuto, Y. Jugnet, J. Massardier, J. C. Bertolini, J. Chem. Soc., Faraday Trans. 92 (1996) 4835

[19] A. Sandell, A. Beutler, A. Jaworowski, M. Wiklund, K. Heister, R. Nyholm, J. M. Andersen, Surf. Sci. 415 (1998) 411.

[20] U. Muschiol, P.K. Schmidt, K. Christmann, Surf. Sci. 395 (1998) 182

[21] Sh. Shaikhutdinov, M. Heemeier, M. Bäumer, T. Lear, D. Lennon, R. Oldman, S. D. Jackson, H.-J. Freund, J. Catal. 200 (2001) 330

[22] D. R. Lloyd, C. M. Quinn, N. V. Richardson, Surf. Sci. 63 (1977) 174.

[23] S. Surnev, M. Sock, M. G. Ramsey, F.P. Netzer, M. Wiklund, M. Borg, M., J.N. Andersen, Surf. Sci. 470 (2000) 171.

[24] T. Mitsui, M. K. Rose, E. Fomin, D. F. Ogletree, M. Salmeron, Nature 422 (2003) 705.

[25] G. Alefeld, J. Völkl (Eds.), Hydrogen in Metals I and II (Topics in Applied Physics), Springer, Berlin, 1978, p. 28-29.

[26] L. Schlapbach, A. Züttel, P. Gröning, O. Gröning, P. Aebi, Appl. Phys. A 72 (2001) 245.

[27] J.-F. Paul, P. Sautet, Phys. Rev. B. 53 (1996) 8015.

[28] Z. Király, Á. Mastalir, F. Berger, I. Dékány, Langmuir 13 (1997) 465.

[29] H. Frieske, E. Wicke, Ber. Bunsenges. 77 (1973) 48.

[30] G. E. Gdowski, T.E. Felter, R.H. Stulen, Surf. Sci. 181 (1987) L147.

[31] W. Eberhardt, S. G. Louie, E. W. Plummer, Phys. Rev. B. 28 (1983) 465.

[32] W. Auer, H. J. Grabke, Ber. Bunsenges. 78 (1974) 58.

[33] S. G. Louie, Phys. Rev. Lett. 40 (1978) 1515.

[34] R. J. Rennard, R. J. Kokes, J. Phys. Chem. 70 (1966) 2543.

[35] H. Molero, B. F. Bartlett, W. T. Tysoe, J. Catal. 181 (1999) 49.

[36] Z. Paál, in: Z. Paál, P. G. Menon (Eds.), Hydrogen Effect in Catalysis, Dekker, New York, 1988.

[37] D. Teschner, D. Duprez, Z. Paál, J. Mol. Catal. 179 (2002) 201.
[38] M. Kaltchev, D. Stacchiola, H. Molero, G. Wu, A. Blumenfeld, W. T. Tysoe, Catal. Lett. 60 (1999) 11.

[39] F. Zaera, Mol. Phys. 100 (2002) 3065

[40] J. A. Gates, L. L. Kesmodel, Surf. Sci. 124 (1983) 68.

[41] W. T. Tysoe, G. L. Nyberg, R. M. Lambert, J. Phys Chem. 90 (1986) 3188.

[42] B. Hugenschmidt, P. Dolle, J. Jupille, A. Cassuto, J. Vac. Sci. Technol. A 7 (1989) 3312.

[43] Y. R. Shen, Nature 337 (1989) 519.

[44] B. J. McIntyre, M. Salmeron, G. A. Somorjai, Rev. Sci. Instrum. 64 (1993) 687.

[45] C. Sachs, M. Hillebrand, S. Völkening, J. Wintterlin, G. Ertl, Science 293 (2001) 1635.

[46] T. W. Hansen, J. B. Wagner, P. L. Hansen, S. Dahl, H. Topsoe, C. J. H. Jacobson, Science 294 (2001) 1508.

[47] J. F. Haw, J. B. Nicholas, T. Xu, L. W. Beck, D. B. Ferguson, Acc. Chem. Res. 29 (1996) 259.

[48] H. Knözinger, G. Mestl, Top. Catal. 8 (1999) 45.

[49] A. Knop-Gericke, M. Hävecker, T. Schedel-Niedrig, R. Schlögl, Top. Catal. 15 (2001) 27.

[50] R. W. Joyner, M. W. Roberts, Chem. Phys. Lett. 60 (1979) 459.

[51] G. A. Somorjai, G. Rupprechter, J. Phys Chem. B 103 (1999) 1623.

[52] F. Garin, G. Maire, S. Zyade, M. Zauwen, A. Frennet, P. Zielinski, J. Mol. Catal. 58 (1990) 185.

[53] H. Bluhm, M. Hävecker, A. Knop-Gericke, E. Kleimenov, R. Schlögl, D. Teschner, V. I. Bukhtiyarov, D. F. Ogletree, M. Salmeron, J. Phys. Chem. B. in press.

[54] V. V. Kaichev, I. P. Prosvirin, V. L. Bukhtiyarov, H. Unterhalt, G. Rupprechter, H.-J. Freund, J. Phys. Chem. B. 107 (2003) 3522

[55] V. I. Bukhtiyarov, I. P. Prosvirin, E. P. Tikhomirov, V. V. Kaichev, A. M. Sorokin, V. V. Evstigneev, React. Kin. Cat. Lett. 79 (2003) 181.

[56] V. I. Bukhtiyarov, Kinet. Catal. 44 (2003) 420.

[57] H.-J. Ruppender, M. Grunze, C. W. Kong, M. Wilmers, Surf. Interface Anal. 15 (1990) 245.

[58] D. F. Ogletree, H. Bluhm, G. Lebedev, C. Fadley, Z. Hussain M. Salmeron, Rev. Sci. Instrum. 73 (2002) 3872.

[59] S. Doniach, M. Sunjic, J. Phys. C 3 (1970) 285.

[60] J. J. Yeh, I. Lindau, At. Data Nucl Data Tables 32 (1985) 1.

[61] S. Tanuma, C. J. Powell, D. R. Penn, Surf. Interface Anal. 17 (1991) 911.

[62] K. S. Kim, A. F. Gossmann, N. Winograd, Anal. Chem. 46 (1974) 197.

[63] M. Todorova, E. Lundgren, V. Blum, A. Mikkelsen, S. Gray, J. Gustafson, M. Borg, J. Rogal, K. Reuter, J. N. Andersen, M. Scheffler, Surf. Sci. 541 (2003) 101.

[64] E. Lundgren, G. Kresse, C. Klein, M. Borg, J. N. Andersen, M. De Santis, Y. Gauthier, C. Konvicka, M. Schmid, P. Varga, Phys. Rev. Lett. 88 (2002) 2461031.

[65] G. A. Somorjai, F. Zaera, J. Phys. Chem. 8 (1982) 3070.

[66] N. M. Rodriguez, P. Anderson, Z. Paál, U. Wild, A. Wootsch, R. Schlögl, J. Catal. 197 (2001) 365.

[67] Z. Paál, U. Wild, R. Schlögl, Phys. Chem. Chem. Phys. 3 (2001) 4644

[68] Z. Paál, R. Schlögl, G. Ertl, J. Chem. Soc. Faraday Trans. 88 (1992) 1179.

[69] I. V. Yudanow, K. M. Neyman, N. Rösch, PCCP 6 (2004) 116.

[70] J. N. Andersen, D. Henning, E. Lundgren, M. Methfessel, R. Nyholm, M. Scheffler, Phys. Rev. B. 50 (1994) 17525. 
[71] F. A. Lewis, The Palladium-Hydrogen System, Academic Press (1967).

[72] R. J. Wolf, M. W. Lee, R. C. Davis, P. J. Fay, J. R. Ray, Phys. Rev. B. 48 (1993) 12415.
[73] P. A. Bennett, J. C. Fuggle, Phys. Rev. B. 26 (1982) 6030. [74] L. Schlapbach, J. P. Burger, J. Physique 43 (1982) L273.

[75] F. Antonangeli, A. Balzarotti, A. Bianconi, P. Perfetti, Sol. Stat. Comm. 21 (1977) 201 